\title{
A VINGANÇA DO FETICHE: REFLEXÕES SOBRE INDÚSŢRIA CULTURAL, EDUCAÇÃO PELA DUREZA E VÍCIO
}

\author{
Antonio Álvaro Soares Zuin ${ }^{*}$
}

\begin{abstract}
RESUMO: Os danos no processo formativo, decorrentes da hegemonia da indústria cultural, são investigados há algum tempo por pesquisadores das áreas de filosofia, psicologia, sociologia e história da educação. De forma geral, concluiu-se que não há uma relação de causa e efeito entre a indústria cultural e a produção de consciências reificadas. Porém, é preciso compreender de que modo o consumidor dos produtos da indústria cultural se esforça para permanecer na condição de objeto, ao invés de ser sujeito de suas açōes. Tem-se como objetivo, neste artigo, refletir sobre a produção e propagação deste impulso conformista. Para tanto, parte-se do seguinte pressuposto: a chave para o entendimento das nuances desse impulso se encontra na análise das transformaçóes históricas da relação entre a indústria cultural e a educação pela dureza.
\end{abstract}

Palavras-chave: Educação pela dureza. Indústria cultural. Fetiche. Vício. Theodor W. Adorno.

THE REVENGE OF THE FETISH: REFLECTION ON THE CULTURE INDUSTRY, EDUCATION THROUGH HARSHNESS AND VICE

ABSTRACT: The impairments of the educational process resulting from the predominance of the culture industry have long been a subject of investigation for researchers in the fields of philosophy, sociology and history of education. Their conclusions usually state that there is no cause-effect relationship between the culture industry and the production of reified consciences. However, one must understand how the consumer of the culture industry products prefers sticking to his condition of object to being the subject of his

* Pós-doutor pela Universidade de Leipzig (Alemanha) e professor-adjunto do Departamento de Educação da Universidade Federal de São Carlos (UfSCAR).

E-mail:dazu@power.ufscar.br

Disponível em <http://www.cedes.unicamp.br> 
A vingança do fetiche: reflexões sobre indústria cultural, educação pela dureza e vício

own actions. This article reflects upon how this conformist impulse is generated and propagated. To this end, it starts from the following postulation: the key to understanding the nuances of this impulse lies in the analysis of the historical transformations of the relation between the cultural industry and the education through harshness.

Key words: Education through harshness. Culture industry. Fetish. Vice. Theodor W. Adorno.

Introdução

V ma das asserções mais intrigantes, para aqueles que se preocupam em pesquisar a relação entre os mecanismos da indústria cultural e os danos no processo formativo, é a seguinte: "Para ser transformado em um inseto, o homem precisa daquela energia que eventualmente poderia efetuar a sua transformação em homem" (Adorno \& Simpson, 1986, p. 146). Se os consumidores dos produtos da indústria cultural são "educados" para que se esforcem a continuar vivendo na condição de insetos, ao invés de canalizarem suas energias para a afirmação da própria conditio humana, então de que forma se produz e se reproduz, no modo de produção capitalista contemporâneo, tal impulso conformista? Tem-se como objetivo, neste artigo, refletir sobre tal questão. Pretende-se argumentar que a compreensão do processo de produção desse impulso conformista se encontra na investigação das transformações históricas da relação entre indústria cultural e a educação pela dureza. No primeiro momento será feita uma análise das origens da educação pela dureza, produzida no contexto histórico da indústria cultural dos anos 60 do século XX. Logo em seguida, serão feitas ponderações sobre a atualidade da indústria cultural e a sua relação com as novas tonalidades da educação pela dureza.

\section{Indústria cultural, educação pela dureza e prazer sadomasoquista}

Se os educadores Borger e Kaduc, ambos citados por Adorno no texto Educação após Auschwitz, fossem questionados sobre como poderiam sintetizar o cerne da metodologia pedagógica defendida por ambos, talvez asseverassem o seguinte: "É fundamental que o professor crie condiçôes para a repressão da angústia de seus alunos, os 
quais precisam aprender que o forte não manifesta sua dor, mas a suporta calado para que possa ser identificado como uma pessoa de caráter". A associação entre educação, formação de caráter e repressão da angústia constitui os alicerces da chamada educação pela dureza. E tal processo "educativo" reforça progressivamente o prazer sadomasoquista, que pode ser fruído tanto na identificação masoquista entre os alunos que são punidos por seus mestres quanto na esperança de que chegará o dia em que eles poderão sadicamente manifestar a dor que tiveram de reprimir, quer seja nos alunos mais novos, quer seja quando se tornarem professores. ${ }^{1}$ No livro de Heinrich Mann, cujo título poderia ser traduzido como Professor lixo, chega a estarrecer o riso sádico dos alunos que mal conseguem disfarçar a satisfação diante da desgraça do professor tirano, que tanto os achincalhou e humilhou (Mann, 2004). Provavelmente, tal riso estarreça porque é expressão, antes de qualquer coisa, de algo demasiadamente humano. Mas o prazer, obtido do exercício da vontade de poder, cujos sinais podem ser identificados nos atos mais tenros de compaixão humana, não pode substituir a necessidade de que professores e alunos sejam responsáveis por uma prática pedagógica não complacente com a repressão da angústia (Adorno, 1971, p. 97).

A angústia reprimida proporciona condiçōes favoráveis ao desenvolvimento da raiva, que gradativamente se transforma no ódio recíproco dos agentes educacionais. Em contrapartida, é ilusório o desejo de a prática pedagógica ser totalmente destituída de violência, pois mesmo as ações pedagógicas caracterizadas como antiviolentas não deixam de ser, e de empregar, certa violência no combate àquela praticada em excesso (Türcke, 1991, p. 21). E se a violência, de um modo ou de outro, pode ser identificada em tais práticas, seria muito mais profícuo e humano se os professores e alunos a assumissem, ao invés de dissimular a sua existência, gerando um clima propício para que as frustrações mútuas pudessem ser expressas, de tal maneira que a raiva não fosse mais reprimida e, portanto, não se transformasse em ódio. $\mathrm{O}$ professor, por exemplo, que reconhece ser um indivíduo sujeito a falhas e acertos como qualquer outro, e que assume o erro de ter sido autoritário em razão de algum descontentamento ocorrido na sala de aula, tem boas possibilidades de ser respeitado e, portanto, verdadeiramente ouvido, quando expressa a importância da disciplina na relação com seus alunos e chama a atenção daqueles que conversam em 
voz alta na sala de aula. É verdade que professores e alunos estão inseridos em relaçôes de poder quantitativamente diferentes. Mas isso não significa que essas mesmas relaçôes tenham de ser marcadas pela violência descontrolada que destrói tanto o respeito quanto os alicerces do processo formativo. As relaçōes entre ambos não precisam ser qualitativamente autoritárias, apesar de hoje prevalecer um caldo de cultura que reconhece como seus aqueles que evitam a "perda de tempo" dos atos de hesitação e, por que não dizer, de reflexão, os quais dever ser renunciados em nome do imperativo: "É isso, e ponto final!".

Atento aos indícios deste clima cultural, Adorno observou as marcas da educação pela dureza não só nas práticas "pedagógicas" de Borger e Kaduc, como também nas manifestações do espírito de um tempo, ou seja, da Alemanha dos anos 60 do século passado, e que mal saíra da experiência do horror da Segunda Guerra Mundial. Poder-se-ia argumentar que períodos históricos, caracterizados por uma devastação tanto do particular quanto do geral, favorecem o aparecimento de uma palavra de ordem autoritária que, ao ecoar, encontra alento no desespero daqueles que anseiam por melhores condiçôes de vida. Porém tal pensamento corre o risco de se transformar num imperativo que transcende e paira acima das condições históricas que o originaram. Daí a relevância da compreensão do contexto no qual Adorno cunhou o conceito de educação pela dureza, ou seja, o contexto da indústria cultural dos anos 60 do século XX. É no auge da chamada revolução técnicocientífica, cujas forças propulsoras foram representadas pelas indústrias do aço, do petróleo, da energia elétrica e da química, que Adorno relaciona as vidas tecnificadas com um processo psicossocial de contínua dessensibilização, a ponto de um dos entrevistados da pesquisa sobre a personalidade autoritária, feita nos Estados Unidos da América na década de 40 do século XX, afirmar que tinha uma boa auto-estima, pois gostava de belos equipamentos. Para Adorno, esta é uma autodefinição conivente com um consciente que se encontra reificado (Adorno, 1971, p. 100).

O processo crescente de tecnificação alastra-se e impregna-se nas esferas mais íntimas, de modo que os objetos produzidos se assenhoreiam dos seus respectivos produtores. Os mesmos produtores que parecem se envergonhar diante da força e do poder dos produtos, cujo brilho ilumina tanto a pretensa onipotência quanto a real debilidade de seus senhores. Günther Anders denominou este fenômeno, de forma bastante su- 
gestiva, como a vergonha prometêutica, numa alusão ao mito de Prometeu, uma vez que o ser humano se incomoda em "apresentar, diante dos olhos dos aparelhos perfeitos, sua patética condição de ser carnal, a imprecisão de sua condição humana. $\mathrm{Na}$ verdade, ele tinha mesmo que se envergonhar diante disso" (Anders, 2002, p. 23). Ironicamente, os aparelhos produzidos pelo ser humano, na qualidade de deus ex machina, passam a ser objeto de desejo e adquirem "vida própria", engendrando um determinado fetiche que, numa leitura psicanalista, estimula o desenvolvimento de uma espécie de identificação com o agressor. Os produtores, agredidos em virtude do fato de que seus produtos espelham tanto a verdade da impotência humana quanto a sua ilusória condição de deus, identificam-se com seus "agressores" e, portanto, ao idealizar possuir tal poder, identificam-se libidinalmente com tais objetos. Já seus fetiches, elevados ao posto de "senhores", não "admitem" mais ser reduzidos à mera condição de objeto (que de fato são), "revoltam-se" contra esta lembrança e se vingam de seus produtores, ao provocar a dependência destes com relação à sua "personalidade". Seguindo esta linha de raciocínio, o conceito de identificação com o agressor, elaborado por Anna Freud (1986), não pode delimitar-se apenas a uma característica da personalidade de algum indivíduo, mas deve ser utilizado para a compreensão do modo como esse indivíduo se identifica com um, digamos, cosmo social agressor (Adorno, 2001, p. 112-113). Ora, se as relaçōes materiais de produção determinam o processo de sociabilização e, portanto, os contornos da identidade do particular de acordo com a lógica do fetiche da mercadoria (Marx, 1984), então a vergonha, projetada nos objetos-mercadoria, considerados verdadeiros refúgios do imediatismo e da vida, tende mesmo a se tornar insuportável. A sensação de frustração conseqüente precisa ser atenuada por meio de uma projeção libidinal mais intensa. E se a vergonha de tal debilidade não pode ser reconhecida, e muito menos debatida numa sociedade ultracompetitiva (pois quem pode hoje em dia assumir a própria fraqueza, sem correr o risco de ser eliminado do trabalho ou da relação íntima?), então resta a promessa de que a dor reprimida possa ser amainada por meio da identificação com os valores de fetiches cada vez mais sedutores e violentos. Nesta perspectiva, é interessante destacar o processo de "humanização" dos fetiches, cujas marcas que os simbolizam passam a ser comercializadas como se fossem portadoras de personalidade própria. Nas últimas décadas do século XIX, observase a preocupação dos produtores de mercadorias em associar seu nome 
A vingança do fetiche: reflexões sobre indústria cultural, educação pela dureza e vício

ao produto para poder destacá-lo com relação à miríade de outros similares, com o objetivo de se estabelecer um vínculo de confiança com os consumidores (Hellmann, 2003, p. 85). Com efeito, as campanhas publicitárias já no século XX, diante do recrudescimento da produção em massa de mercadorias, concentraram-se na afirmação da "idiossincrasia" do produto, uma vez que, por exemplo, não se comprava um automóvel qualquer, mas sim uma Ferrari. ${ }^{2} \mathrm{O}$ poder do fetiche chega a ser tamanho que o produto não só adquire o nome de seu produtor, mas é vendido como se tivesse uma personalidade que já "nascera" com ele, como se fosse realmente absoluto.

O próprio Adorno reconheceu a dificuldade de se identificar os limites entre as atitudes patológica e não-patológica com relação aos produtos da técnica humana (Adorno, 1971, p. 99). E se as pessoas se tornam tecnologizadas, haja vista o assombro diante da facilidade com que as crianças da nova geração manuseiam os comandos do teclado do computador, as benesses produzidas (que não são poucas) não podem obnubilar o fato de que as mesmas pessoas tendem a considerar a técnica de forma absoluta, como se fosse algo em si, em vez de ser um produto do trabalho humano. E o discernimento crítico desta fronteira se enfraquece na mesma proporção em que a indústria cultural promete a satisfação imediata do prazer, mas, na verdade, incentiva a substituição do prazer pelo pré-prazer, que também se absolutiza. Adorno e Horkheimer, na análise da dialética do esclarecimento, já diziam que

A indústria cultural não sublima, mas reprime. Expondo repetidamente o objeto do desejo, o busto no suéter e o torso nu do herói esportivo, ela apenas excita o prazer preliminar não sublimado que o hábito da renúncia há muito mutilou e reduziu ao masoquismo. Não há nenhuma situação erótica que não junte à alusão e à excitação a indicação precisa de que jamais se deve chegar a esse ponto... A produção em série do objeto sexual produz automaticamente seu recalcamento. (Ádorno \& Horkheimer, 1986, p. 131)

O processo de dessublimação, patrocinado pela indústria cultural, parece mesmo lançar às favas as dolorosas conquistas humanas obtidas por meio do confronto entre as imposições do desejo e as possibilidades reais de sua satisfação. E se a razão é desejo traduzido (Türcke, 2002, p. 307), a indústria cultural, por sua vez, assume a tarefa de interpretação dos códigos do desejo, ao prometer-lhe o prazer pleno, sem quaisquer tipos de obstáculos. Porém, é este prazer preliminar, este pré- 
prazer não sublimado que é cada vez mais excitado até chegar ao ponto de se metamorfosear em sucedâneo do prazer. $^{3}$ A excitação dos movimentos iniciais do prazer ocorre em todas as situações que impulsionam o organismo para ações que possibilitem a concretização daquilo que fora desejado. Mas quando o pré-prazer é inflacionado de forma compulsiva, então o sofrimento que advém da frustração e do logro se converte em fonte de prazer sadomasoquista. E se desde a Dialética do esclarecimento já se sabe que a indústria cultural incita o estágio preliminar do prazer, ao mesmo tempo em que interdita a realização do próprio prazer, de que modo este processo psicossocial poderia ser caracterizado na sociedade cujas pessoas se viciam nos choques audiovisuais produzidos pela atual indústria cultural? A seguir, serão apresentados subsídios conceituais para a resposta desta questão.

\section{Educação pela dureza, choque e vício}

Quando Adorno e Horkheimer afirmaram, na Dialética do esclarecimento, que "a diversão é o prolongamento do trabalho no capitalismo tardio" (Adorno \& Horkheimer, op. cit., p. 128), ambos se referiram à relação de proximidade entre as lógicas das esferas do trabalho e do lazer. Acostumado com a confecção de operaçóes padronizadas durante a sua jornada de trabalho, o indivíduo năo consegue desvencilhar-se do exercício do pensamento mecanizado, que encontra espaço também nas chamadas atividades de lazer. No caso do filme de sucesso, cujo título, em muitas ocasiōes (mas não todas), já antecipa grande parte do enredo que será posteriormente conferido, a ponto de não existir o risco de surpresas diferentes daquelas já esperadas, os reflexos pavlovianos dos espectadores "surpreendem-se" com a cena de terror previamente anunciada pelos ruídos da música assustadora.

Se os frankfurtianos observaram tal proximidade entre as lógicas do trabalho e do lazer já em meados da década de 40 do século XX, como poderíamos refletir sobre tal relação no capitalismo transnacional, o palco da revolução microeletrônica? No contexto atual, a simbiótica relação entre trabalho e lazer realiza, embora às avessas, a fusão entre trabalho e tempo livre, que fora antigamente privilégio de determinadas profissões, tais como os artistas e intelectuais, cujo trabalho não podia ser diferenciado das atividades de lazer. Nas relaçôes de produção capitalistas hodiernas, o vínculo entre tempo livre e trabalho recebe contornos 
A vingança do fetiche: reflexões sobre indústria cultural, educação pela dureza e vício

inéditos. Há uma pressão (que também é uma compulsão) para emitir (Sendezwang), sendo que tal pressão se torna $a$ força de sucção do capitalismo sob condições microeletrônicas. O campo de atuação do computador não se circunscreve apenas ao de um instrumento de trabalho, mas metamorfoseia-se num aparelho que possibilita: a realização de encontros sociais e particulares, processamento e transmissão de dados, a elaboração de atividades de trabalho e de diversão, televisão e comunicação, concentração e dispersão, ser ignorado ou ser percebido, a ponto de todas essas potencialidades se tornarem indiscerníveis entre si (Türcke, 2002, p. 43). Quando um adolescente, que ainda não enviou uma mensagem por e-mail, diz de si próprio: "ainda não me conectei”, então tal jargão da juventude retrata a lei fundamental de uma nova ontologia: quem não se conecta não é percebido e, portanto, não existe. Para Türcke:

E tal como a força de integração do mercado nunca foi apenas uma força econômica ou nunca apenas determinou a possibilidade de se ter ou não emprego, mas sempre determinou o ser aceito ou rejeitado e, portanto, ser ou não ser, essa pressão ontológica, sob as condiçôes gerais da pressão para emitir, se transformou numa forma estética, ao mesmo tempo em que o estético recebe, como nunca ocorreu anteriormente, um peso ontológico. E isso também se conecta ao ser éser percebido. Assim se expressa a ontologia paradoxal dos tempos microeletrônicos: uma existência sem a presença eletrônica é um aqui e agora sem um aí, ou seja, trata-se de uma não-existência viva. (Ibid., p. 64)

De fato, saltam aos olhos os efeitos das transformações estéticas, ou melhor, das novas formas de percepção que são estimuladas na medida em que os indivíduos não só se acostumam como também exigem o contato com choques imagéticos numa freqüência cada vez maior. Quanto mais as pontas dos dedos, os movimentos oculares e até mesmo a postura corporal são "atados" a equipamentos microeletrônicos, com um grau inaudito de precisão psicomotora, mais afirma-se o que se pode denominar como a exploração da capacidade de concentração. $\mathrm{E}$ isso ocorre tanto na esfera do trabalho quanto na do tempo livre, as quais são praticamente indiscerníveis. Tanto no uso do computador no trabalho quanto na sua utilização particular na residência, a concentração, canalizada para uma determinada informação, é logo em seguida triturada por meio de incontáveis repetições na forma de links, de tal modo que "o meio de concentração se torna o próprio meio de decomposição" (ibid., p. 273). 
Se na imanência do próprio modo de produção capitalista se encontra uma dinâmica que vicia, atualmente ela se apresenta na forma do vício dos choques audiovisuais. Não é obra do acaso a compulsão de verificarmos, num intervalo de tempo cada vez menor, se somos observados por novas mensagens que abastecem a caixa de e-mails, ou então a avidez dos adolescentes (e, em muitos casos, a dos adultos) por computadores, pois passam madrugadas inteiras "conectados" a outros adolescentes. A presença de tais práticas obsessivas remete o pensamento para a compreensão das características do processo psicossocial no qual o vício do choque audiovisual se arvora. E é justamente um texto de Sigmund Freud, certamente um dos seus escritos mais controversos, que oferece o aparato conceitual para o entendimento de tal processo. Refiro-me ao Além do princípio do prazer. Na investigação da relação entre a falta de preparação para a angústia e a produção de choques traumáticos, Freud observou que

Ver-se-á, então, que a preparação para a angústia e a hipercatexia dos sistemas receptivos constituem a última linha de defesa do escudo contra estímulos. No caso de bom número de traumas, a diferença entre os sistemas que estão despreparados e sistemas que se acham bem preparados através da hipercatexia pode constituir fator decisivo na determinação do resultado. (Freud, 1998, p. 40)

Se existe a denominada preparação para a angústia, ou seja, se os sistemas receptivos conseguem condensar as energias psíquicas em representações mentais capazes de formar as defesas contra a força dos estímulos, há grandes chances de que não se desenvolvam os sintomas referentes aos choques traumáticos. Mas talvez nem mesmo Freud pudesse imaginar a existência de uma sociedade que incentivasse a busca compulsiva pelo choque, transformado em fonte de prazer sadomasoquista. Neste contexto, que tipo de hipercatexia, que tipo de ligação psíquica pode ser elaborada no contato com a violência, muitas vezes devastadora, dos choques provenientes dos produtos da atual indústria cultural? Ora, a verdade de que não se pode estabelecer uma relação de causa e efeito entre o hábito dos freqüentadores de parques de "diversão", que se jogam da altura de 30 metros com os pés atados a uma corda elástica, e a produção de choques traumáticos (uma vez que alguma catexia psíquica é formada, pois caso contrário haveria uma espécie de surto psíquico generalizado), não pode obstar a constatação de 
A vingança do fetiche: reflexões sobre indústria cultural, educação pela dureza e vício

que há uma dinâmica viciadora no consumo dos produtos da indústria cultural. Os mesmos produtos que precisam ser cada vez mais agressivos para que possam destacar-se com relação a outros produtos e, portanto, ser consumidos.

Freud já afirmara que quaisquer processos afetivos mais intensos que ultrapassassem um certo limite, tais como as excitaçôes assustadoras e angustiantes, seriam propagados para a sexualidade, ou seja, teriam um efeito sexualmente excitante. Para o psicanalista, isso explicaria o fato de muitas pessoas sentirem prazer no contato com situações que engendrassem afetos aparentemente desprazerosos, tais como angústia, medo ou horror, desde que houvesse algum tipo de circunstância secundária que atenuasse um pouco a gravidade da sensação desprazerosa (Freud, 2004, p. 105). Mas o que dizer de uma sociedade que se curva, em sinal de reverência, diante da fascinação do grotesco e, por que não dizer, do horror? É verdade que tal fascínio acompanha a história da humanidade desde os seus primórdios, pois foram as incontáveis repetiçôes dos choques traumáticos, produzidas por meio dos rituais de sacrifício, por exemplo, que possibilitaram que o horror fosse catexizado em representaçôes mentais capazes de produzir uma sensação de controle (Türcke, 2002, p. 289). Contudo, na sociedade da indústria cultural contemporânea, o trato com o horror é outro. Talvez não seja equivocada a argumentação de que o horror atualmente tanto seduz porque os choques, por meio dos quais ele se manifesta, excitam exatamente os componentes sadomasoquistas da pulsão sexual, ou melhor, os componentes sadomasoquistas das circunstâncias iniciais da pulsão sexual, as denominadas pulsões parciais, de tal maneira que duas dessas pulsōes parciais se entrelaçam e se completam: as pulsóes do prazer de olhar e exibir e a de crueldade. No transcorrer do processo psicossocial do indivíduo, ambas as pulsões podem ser estimuladas em excesso, principalmente durante a infância. Pode então ser gerada uma situação na qual o préprazer, associado a estas pulsões, seja de tal modo excitado que se desenvolva uma fixação obstaculizadora da trajetória "normal" da pulsão sexual. Mas, atualmente, a afirmação da força do pré-prazer fundamenta-se na promessa de que os "novos" produtos da indústria cultural seriam mais sedutores e excitantes que a realização do próprio sexo, reforçando assim a dinâmica psicossocial viciadora da sociedade capitalista transnacional. 
Daí a importância que o prazer de olhar e exibir adquire, pois, se o estético atualmente recebe um peso ontológico inaudito, ou seja, se hoje ser é ser percebido, isso só ocorre caso os estímulos provem que sua violência também é "inédita", "original", de tal modo que tenham êxito em fascinar o olhar, conquistando a disputada atenção do indivíduo que os consome e que passa a exibir os ícones dos produtos da indústria cultural associados a esses estímulos, com a esperança de sentir o prazer de ser notado, de ser percebido por outras pessoas. De acordo com uma leitura psicossocial, tais estímulos provocam as excitações sexualmente angustiantes, que encontram esteio nos elementos sadomasoquistas da pulsão parcial do prazer de olhar e exibir, a mesma pulsão que "seduz" o organismo e o convence a voltar a consumir avidamente os estímulos agressivos dos choques imagéticos. Torna-se, portanto, inevitável a lembrança dos programas de auditório de televisão, sucessos de audiência em países tais como Brasil, Itália, Estados Unidos da América e Alemanha, cujos apresentadores recebem pessoas dispostas a expor publicamente as suas misérias objetivas e subjetivas. E isso não porque tenham a esperança de receber alguma palavra de conforto para os respectivos fardos íntimos, mas sim pela possibilidade de serem vistos e terem a sensação de que a miséria pessoal é atenuada pela confirmação cruel da própria existência, "comprovada" sadomasoquistamente por milhōes de pessoas. O prazer de ser percebido pelos telespectadores, os quais se identificam sadomasoquistamente com o desafortunado que teve a fortuna de ser observado por milhões, compensa a vergonha que poderia ser sentida em virtude da confissão pública da própria debilidade. E o voyeurismo sadomasoquista é inflacionado pelo consumo dos choques audiovisuais de outros programas de televisão, tais como No limite (Brasil), Survivor ("Sobrevivente", EUA), Ich bin ein Star ("Eu sou uma estrela", Alemanha), cujos participantes devem passar por provas asquerosas, tais como o contato com animais peçonhentos, até que reste apenas o mais "resistente", o mais "forte" de todos, na verdade o mais insensível.

Trata-se mesmo de um mecanismo perverso, pois o prazer sadomasoquista que tais choques audiovisuais proporcionam cobra seu preço na danificação do processo educativo/formativo. Ocorre que, além de frágeis, são por demais insuficientes as ligações iniciais entre os estímulos e as representações mentais. O neurônio "comemora" o recebimento de um quantum sobre-humano de excitação, mas a velo- 
A vingança do fetiche: reflexões sobre indústria cultural, educação pela dureza e vício

cidade e a força de apresentação de tais estímulos, as quais dependem da velocidade de reposição das "novas" mercadorias, dificultam a possibilidade de que a sensação possa, digamos, criar raízes a ponto de estimular a criação de representações mentais duradouras que poderiam auxiliar o processo de construção de experiências formativas. ${ }^{4}$

E são os fetiches, como sucedâneos das experiências humanas, que se vingam de seus criadores por meio de uma dinâmica que vicia $\mathrm{e}$ que produz um estado semelhante ao da síndrome de abstinência. A poderosa metralhadora audiovisual, para usar uma expressão de Christoph Türcke, dispara seus projéteis nas mais variadas situações do cotidiano e, tal como se fosse uma injeção audiovisual, excita o aparelho perceptivo, ao mesmo tempo em que impulsiona o indivíduo a fruir o choque audiovisual compulsiva e sadomasoquistamente, até chegar ao ponto de ele se transformar em vício. A exemplo do viciado em drogas, o viciado pelo choque audiovisual sabe, no seu íntimo, que a substância viciadora não tem o efeito redentor desejado, mas mesmo assim seu organismo "crê" na promessa de felicidade da substância e não pára de exigi-la, até porque o mal-estar decorrente de tal contradição é arrefecido pelo prazeroso voyeurismo sadomasoquista citado anteriormente. É nessa perspectiva que a dinâmica do vício se confunde com a da crença fundamentalista, pois o "vício é, por assim dizer, a crença que se alça sobre a base da descrença" (Türcke, 2002, p. 253). A procura desesperada por mais substância viciadora, no caso o contato com estímulos audiovisuais mais potentes, denuncia também o desejo do viciado em querer se livrar do vício, pois ele sente de alguma forma que está sendo ludibriado ao consumir imagens que são sucedâneos do real, mas que são apresentadas com se fossem verdadeiramente tal real.

Qualquer imagem representa um fato real ou fictício, mas a sua proximidade com o real é hoje tão simulada que o abstrato e o concreto parecem se fundir. Porém, nesse caso, "o abstrato e o concreto não se colocam, num contexto de referência, nas condições de significado e significante, de essência e aparência, pois eles não significam e representam um ao outro, mas sim se penetram e se tornam irreconhecíveis entre si" (idem, ibid., p. 288). O resultado disso é um dano poderoso no processo de produção de representações mentais, as quais praticamente perdem seu poder de simbolização e, portanto, seu "chão", seu lastro histórico. E talvez hoje estejamos vivenciando exatamente esta metamorfose da educação pela dureza, cujas características não se atre- 
lam "apenas" às situações do cotidiano escolar nem mesmo ao clima cultural da Alemanha da década de 60 do século XX. Suas nuances são ilustradas na angústia, atualmente exposta de modo repressivo e, portanto, na prática de um processo "formativo" sadomasoquista de uma sociedade cuja indústria cultural produz injeçōes audiovisuais em toda parte. Como foi observado anteriormente, Adorno criticou, no texto Educação após Auschwitz, o aceite de uma prática "pedagógica" que premiasse o comportamento do aluno capaz de não demonstrar quaisquer sinais de fraqueza, ou de hesitação, diante da palavra de ordem áspera de seus preceptores. Era necessário não se manifestar durante as chamadas atividades "pedagógicas", pois o adolescente de caráter seria recompensado por ter conseguido suportar quaisquer tipos de sofrimentos físico e psicológico.

Já na sociedade atual, os adolescentes são "educados", no consumo dos choques imagéticos dos produtos da indústria cultural, a expor publicamente a sua angústia, porém de forma repressiva. Não é mais preciso sofrer calado, pois o contato com os agressivos choques imagéticos permite a exposição sádica da dor masoquistamente reprimida, tanto dentro quanto fora das escolas. E isso produz prazer, um prazer que vicia. Obviamente, não se deve fazer uma relação de causa e efeito entre os adolescentes que se viciam no jogo de vídeo True crimes (e que comemoram efusivamente cada vez que "matam" um velho, uma criança ou um ladrão) e a prática de assassinatos reais. ${ }^{5}$ Mas a fruição do prazer sádico, que os choques audiovisuais de tal jogo possibilitam, não pode ser descontextualizada, ou seja, não pode ser exclusivamente considerada como uma característica da personalidade de um determinado indivíduo, pois deve ser identificada como prática simpática ao incremento da dessensibilização, a mesma dessensibilização que se transforma numa conduta de vida engendrada por um caldo cultural historicamente produzido. Nesse contexto, a indústria cultural contemporânea assume a direção do processo "formativo", pois é ela quem determina as características da atual educação pela dureza.

A exigência da ausência de reflexão, o elogio do fazer pelo fazer sem que haja qualquer hesitação, o reconhecimento dos "fortes" que não sentem medo e que ultrapassam todos os obstáculos para suas ações, reaparecem nos princípios "pedagógicos" da nova educação pela dureza. Mas as características de tais princípios, diferentemente do sofrer em silêncio que compunha a matriz da educação pela dureza do século passado, reverberam no riso e no choro de identificação sadomasoquista do telespec- 
A vingança do fetiche: reflexões sobre indústria cultural, educação pela dureza e vício

tador diante das provações que os participantes de programas do tipo No limite devem suportar ou ante as tragédias particulares que são expostas nos programas de televisão de auto-ajuda. E verdade que a confissão da dor e da angústia reprimidas proporciona alívio. Contudo, isso ocorre de forma repressiva, pois o preço de tal catarse é cobrado na submissão do indivíduo à violência sedutora dos fetiches audiovisuais. E a sensação de onipotência, derivada da identificação com as promessas desses fetiches de que não há limites para a imposição da vontade própria, "resolve", num piscar de olhos, o conflito entre as exigências do desejo e suas possibilidades de realização, ao mesmo tempo em que se converte num duro golpe à esperança de disseminação da experiência formativa. A mesma experiência que não se furta de enfrentar o desafio kantiano da obtenção da liberdade em meio às práticas sociais coercitivas, e que fora consubstanciada ao sonho de que o conceito não seria tão apartado da sua realização objetiva, de tal modo que as pessoas que aprendessem aquilo que Paulo Freire, Sartre e Adorno escreveram sobre o conceito de preconceito se sentiriam estimuladas a rever efetivamente suas atitudes preconceituosas. Mas tal iniciativa não depende exclusivamente da vontade do indivíduo, pois, como foi observado anteriormente, a sociedade da atual educação pela dureza acolhe como seus aqueles que evitam a todo custo o exercício da reflexão e observam com indiferença o sofrimento alheio, indiferença esta que se "sensibiliza" novamente diante do êxito do acontecimento que consegue chocar mais do que seus concorrentes. Deste quadro resulta a frialdade que penetra em todas as relaçóes humanas. Não que as pessoas fossem indiferentes ao sofrimento alheio apenas no capitalismo, mas é nesse modo de produção da existência humana que a frieza adquire caráter normativo e se transforma numa forma de percepção (Gruschka, 1994, p. 35 e 43), de tal maneira que ocorre o recrudescimento da frieza, da dessensibilização em meio à superexcitação do aparato perceptivo. E o jovem não deixa de reagir diante desta contradição, uma vez que sua revolta, ainda que seja conformista, exprime-se em várias ocasiōes, tal como na propagação do uso do piercing, por exemplo.

O malogro, sentido diante da redução da capacidade de intervenção, é ilusoriamente reduzido, pois o jovem, por meio do uso dos piercings, expõe sadicamente o logro que fora obrigado a masoquistamente suportar, ou seja, o logro de que seus desejos são mesmo atendidos. A angústia é exposta, repressiva e violentamente, no corpo de tal adolescente, que protesta publicamente contra a falsidade da promessa 
de liberdade que lhe é oferecida, ainda que seja um protesto conformista rapidamente absorvido pela indústria cultural como mais uma moda, a exemplo da indústria hippie. Mas, se esse protesto fosse verdadeiramente ouvido, sua súplica poderia ser traduzida da seguinte forma: "Olhe o que vocês estão fazendo comigo. Estão satisfeitos? Ou querem mais?".

Porém no capitalismo há sempre espaço para este "mais", pois, se a personalidade se torna cada vez mais reificada, o corpo não escapa desta lógica. O desejo do mesmo adolescente de transformá-lo numa máquina perfeita, expressão bastante simpática à atual educação pela dureza, já revela o seu próprio processo de coisificação. E esse desejo se torna a prioridade da vida, a qual pode converter-se na morte, haja vista a quantidade de jovens anoréxicos, "educados" a se espelharem num modelo de corpo doentio veiculado pela mídia da moda. Esses jovens, na maior parte garotas, recusam-se a comer por medo de engordar e falecem numa freqüência cada vez mais difícil de ser ignorada, ainda que nos esforcemos em não considerá-la. Tal como o artista da forme, do conto de Kafka (1991), os corpos de tais adolescentes também se deterioram, mas há uma significativa diferença entre ambos, pois se o artista circense definha aos poucos e morre solitário, enquanto a atenção do público se volta para o corpo exuberante da jovem pantera que o substitui, já as imagens dos corpos dos adolescentes anoréxicos são sadomasoquistamente consumidas por milhôes, nas telas dos computadores e nas reportagens de televisão, ao vivo e on-line. ${ }^{6}$ Mas a indignação, perante estes corpos que são explorados como mórbida publicidade nos noticiários televisivos, é rapidamente esquecida diante do fascínio provocado pelo vigor da pantera contemporânea, ou seja, pela imagem do atleta, cujo corpo escultural divulga os produtos das marcas Reebok ou Nike nas propagandas comerciais dos intervalos desses mesmos noticiários.

Os princípios "pedagógicos" da atual educação pela dureza, tais como o incentivo à sensação de onipotência, à dessensibilização e à ausência de reflexão, espraiam-se para vários países, pois são cinicamente resumidos nos imperativos categóricos Não tenha medo, Não há limites e Faça isto! (Reebok e Nike). E a dureza, nos dias de hoje, manifesta-se dissimuladamente na aparência da concessão plena (exposta exemplarmente em tais logotipos) que, na verdade, nunca se efetiva. $\mathrm{O}$ sucesso de tais marcas não se deve apenas ao enorme capi- 
A vingança do fetiche: reflexões sobre indústria cultural, educação pela dureza e vício

tal investido nas campanhas publicitárias, mas também ao fato de que seus imperativos tiveram êxito em traduzir tais princípios "pedagógicos" da educação pela dureza já vigentes (sobretudo a associação entre onipotência e frieza), os quais se fortalecem ao mesmo tempo em que auxiliam o recrudescimento da força dessas marcas. Em comparação com a força de propagação mundial desses logotipos, chega a ser risível o alcance dos jingles publicitários do início do século XX, os quais já exaltavam a "personalidade" das marcas dos produtos comercializados. A marcas atuais assumem tanto a condição de sujeito, que parecem não mais representar os respectivos objetos, mas sim os substituem, como se as imagens de tais logotipos se tornassem sucedâneos do próprio real. E quando adquirem "vida própria", vingam-se de seus produtores. Os mesmos produtores que se tornam cada vez mais seduzidos pelas idiossincrasias de seus fetiches, pois identificam-se libidinalmente com seus "agressores" e participam ativamente de sua submissão. Eles são "educados" a se esforçar para continuar a ser insetos, ao invés de usar a energia que poderia ser revertida para a afirmação da própria condição humana, pois viciam-se no consumo dos estímulos dos choques audiovisuais dos produtos da indústria cultural. E mesmo que sejam alertados pela voz sussurrante da consciência sobre a dinâmica viciadora deste processo, dificilmente deixam de se aferrar à própria submissão, haja vista que tal advertência tende a se esvaecer diante do grito do organismo que suplica compulsivamente por overdoses de estímulos audiovisuais e que é "anestesiado", ao menos momentaneamente, de sua dor por meio da fruição do prazer sadomasoquista. O mesmo prazer que "compensa" a frustração decorrente da falsidade das promessas da indústria cultural, pois quem tudo promete é porque, na realidade, nada concede. Esta é a "lição" da educação pela dureza, que é, atualmente, aprendida a duras penas, principalmente pelos adolescentes: a revolta, exposta por meio das "concessōes" feitas pela indústria cultural, bem como a fruição do prazer sadomasoquista dela decorrente reafirmam sua condição de objeto ao mesmo tempo em que arrefecem a vergonha derivada de tal condição. Os agressivos logotipos, com os quais os adolescentes associam as respectivas identidades e, assim, transformam-se em vitrines vivas, proporcionam a falsa sensação de onipotência, uma vez que conquistam o olhar dos outros e se destacam no meio de outros estímulos visuais. Ser é ser percebido, de preferência da forma mais violenta. E se a vergonha que o Prometeu do século XX sentira, na comparação entre a sua fragilidade e a força de seus próprios pro- 
dutos, poderia representar a primeira fagulha de um processo de autocrítica e, portanto, de discernimento sobre a relação dialética entre barbárie e progresso técnico, já na atual sociedade do gosto pelo choque audiovisual tal vergonha é rechaçada diante da inflação compulsiva do pré-prazer e da promessa de felicidade dele decorrente. No capitalismo transnacional, o Prometeu envergonhado transforma-se no indivíduo que se identifica, na condição de viciado, com o poder do fetiche, com a opulência de seu "agressor".

\section{Conclusão}

Mas mesmo em tal identificação, mesmo no esforço que o indivíduo faz, muitas vezes consciente, de se agarrar ao vício do choque audiovisual e perpetuar a sua condição de dependência, pode-se identificar a presença de uma revolta latente, de um desejo de ruptura com tal condição de subsunção. E o irônico disso tudo é que, na sociedade excitada, os atos de contestação, os quais podem derivar para ações de resistência, são também percebidos de forma sensacional, tal como no caso das manifestações de protesto realizadas em 2001 na cidade de Gênova pelo grupo italiano Tutte Bianche: ${ }^{7}$ seus membros, vestidos com macacóes brancos, tais como verdadeiros espectros, tornaram visíveis os seres cuja humanidade desaparecera nas condições de pessoas sem trabalho, sem teto e sem direitos (Türcke, 2002, p. 321). Quando a força das imagens provoca o efeito de um choque que desvela a complexidade de uma situação social, então esse choque imediato se metamorfoseia num choque que estimula a reflexão, uma vez que as imagens se transformam em imagens-pensamento (Benjamin, 1972, p. 305), cuja essência foi traduzida poeticamente nesta premonitória frase de Karl Kraus: "Quanto mais de perto se olha a palavra, para mais distante ela remete de volta o olhar" (Kraus, 1986, p. 291). Tais imagens-pensamento são a prova viva de que algo mais pode ser feito além daquilo que já foi, pois elas permitem, por meio de seu poder de simbolização, a religação do particular com o mediato historicamente produzido, com a sua história, algo tão caro à experiência educacional/formativa. Assim, parafraseando Karl Kraus, poder-se-ia asseverar que, em certas ocasiōes, quanto mais de perto se olha a imagem, para mais distante ela remete de volta o olhar. Mas mesmo a mais poderosa imagem-pensamento nunca deixa de ser a $r e-$ 
A vingança do fetiche: reflexões sobre indústria cultural, educação pela dureza e vício

presentação de algo, pois, no limite, a esperança de que o objeto não devolva um olhar enraivecido e vingativo ao seu criador depende de que as relações objetivas entre os seres humanos cessem de ser relações entre objetos, entre coisas.

Recebido em abril de 2005 e aprovado em dezembro de 2005.

\section{Notas}

1. A respeito das formas como alunos e professores manifestam destrutivamente a angústia reprimida, cf. Zuin, 2002.

2. Na Itália, as pessoas referem-se aos carros produzidos pela fábrica de automóveis Ferrari como la macchina ( $o$ carro), fato este que ilustra o modo como o objeto-mercadoria se transforma em algo em si, ou seja, num absoluto.

3. Marcuse (1986) denominou este processo como dessublimação repressiva.

4. A experiência formativa não se esgota no processo de auto-reflexão, mas procura exercer o conceito aprendido na prática cotidiana, uma vez que há uma reapropriação do conteúdo histórico que lhe é imanente. Portanto, não adianta saber, por exemplo, o que Paulo Freire escreveu sobre preconceito se as açôes cotidianas continuam sendo preconceituosas. Recuperar a história imanente ao próprio conceito significa religar-se, objetiva e subjetivamente, com a história humana.

5. No jogo de vídeo True crimes, um policial mata, nas ruas de Los Angeles, criminosos e também velhos ou crianças que possam estar atrapalhando a realização de seu trabalho.

6. Um estudo detalhado sobre a história cultural dos distúrbios alimentares encontra-se em Vandereycken et al., 2003.

7. Trata-se de um grupo antiglobalizacão, que se tornou mundialmente conhecido após protestar contra a política econômica dos países que compõem o bloco do G8.

\section{Referências bibliográficas}

ADORNO, T.W. Erziehung nach Auschwitz. In: Adorno, T.W. Erziehung zur Mündigkeit. Frankfurt am Main: Suhrkamp, 1971.

ADORNO, T.W. Zur Lehre von der Geschichte und von der Freiheit: Nachgelassene Schriften. Frankfurt am Main: Suhrkamp, 2001.

ADORNO, T.W.; HORKHEIMER, M. A indústria cultural: o esclarecimento como mistificação das massas. In: Adorno, T.W.; Horkheimer, M. Dialética do esclarecimento: fragmentos filosóficos. Trad. de Guido Antonio de Almeida. Rio de Janeiro: Zahar, 1986. 
ADORNO, T.W.; SIMPSON, G. Sobre música popular. In: CoHN, G. (Org.). Theodor W. Adorno. Trad. de Flávio R. Kothe. São Paulo: Ática, 1986.

ANDERS, G. Die Antiquiertheit des Menschen I. München: C. H. Beck, 2002.

BEnjamin, W. Denkbilder. In: Benjamin, W. Gesammelte Schriften. Frankfurt am Main: Suhrkamp, 1972. v.4.

FREUD, A. O ego e os mecanismos de defesa. Trad. de Álvaro Cabral. Rio de Janeiro: Civilização Brasileira, 1986.

FREUD, S. Além do princípio do prazer. Trad. de Christiano Monteiro Oiticica. Rio de Janeiro: Imago, 1998.

FREUD, S. Drei Abhandlungen zur Sexualtheorie. Frankfurt am Main: Fischer, 2004.

GRUSCHKA, A. Bürgeliche Kälte und Pädagogik. Wetzlar: Büsche der Pandora, 1994.

HELLMANN, K.U. Soziologie der Marke. Frankfurt am Main: Suhrkamp, 2003.

KAFKA, F. Um artista da fome/A construção. Trad. de Modesto Carone. São Paulo: Brasiliense, 1991.

KRAUS, K. Aphorismen. Frankfurt am Main: Suhrkamp, 1986.

MANN, H. Professor Unrat. Hamburg: Rororo, 2004.

MARCUSE, H. A ideologia da sociedade industrial: o homem unidimensional. Trad. de Giasone Rebuá. Rio de Janeiro: Zahar, 1986.

MARX, K. Fetichismo e reificação. In: Ianni, O. (Org.). Karl Marx. Trad. de Reinaldo Sant'Anna. São Paulo: Ática, 1984.

TÜRCKE, C. Violenza e tabu. Milano: Garzantini, 1991.

TÜRCKE, C. Erregte Gesellschaft: Philosophie der Sensation. München: C. H. Beck, 2002. 
A vingança do fetiche: reflexôes sobre indústria cultural, educação pela dureza e vício

VANDEREYCKEN, W. et al. Wundermädchen, Hungerkünstler, Magersucht: eine Kulturgeschichte der Ess-Störungen. Weinheim: Beltz, 2003.

ZUIN, A.A.S. O trote na universidade: passagens de um rito de iniciação. São Paulo: Cortez, 2002. 